\title{
Yozgat Yöresi Yemek ve Tatlı Kültürünün Sürdürülebilirliği
}

\section{Sustainability of Food and Dessert Culture in Yozgat Region}

\author{
Selma Korkmaz* \\ Tülay Kaya Tekman**
}

\begin{abstract}
Öz
Yozgat hem çok fazla göç alan hem de çok göç veren bir ildir. Bundan dolayı Yozgat halkının kültürel değerlerini devam ettirip ettirmediği merak konusudur. $\mathrm{Bu}$ çalışmanın amacı güncel koşullarda Yozgat halkının yemek ve tatlı kültürünü bilip bilmediklerini ortaya çıkarmaktır. Çalışma grubu, aslen Yozgatlı olup da gerek Yozgat'ta gerekse Türkiye'nin çeşitli illerinde ve yurtdışında yaşayan 50 kadından oluşmaktadır. Veri toplama aracının oluşturulması esnasında 3 halk eğitimcisinin görüşüne başvurularak 5 ana, 3 de alt sorudan meydana gelen toplam 8 soru tercih edilmiştir. Böylece verilerin toplanmasında 8sorudan oluşan bir görüşme formu kullanılmıştır. Bu görüşme formu aracılığıyla, Yozgatlı kadınların, yaş ve çalışma durumu değişkenleri göz önünde bulundurularak Yozgat yemek ve tatlı kültürünü ne kadar bildikleri ortaya çıkarılmıştır. Elde edilen verilerin çözümlenmesinde ise içerik analizinden yararlanılmış; veriler belli kategorilerle temalara ayrılarak frekans ve yüzdeliklerle gösterilmiş, çeşitli karşılaştırmalar yapılmıştır. Elde edilen bulgular neticesinde 46-70 yaş arasındakilerin 20-45 yaş aralığındakilere, çalışmayanların da çalışanlara nazaran Yozgat yöresi yemek ve tatlı kültürünü çok daha iyi
\end{abstract}

Geliş tarihi (Received):10.05.2020 - Kabul tarihi (Accepted): 23.12.2020

* Yrd. Doç. Dr., Yakın Doğu Üniversitesi Eğitim Fakültesi Türkçe Öğretmenliği Ana Bilim Dalı. selma.korkmaz@, neu.edu.tr. ORCID 0000-0003-2395-9751

**Uz., Yakın Doğu Üniversitesi Eğititm Fakültesi Türkçe Öğretmenliği Ana Bilim Dalı. tulay.kaya@neu.edu.tr. ORCID 0000-0003-0200-047X / CC BY 
bildikleri tespit edilmiştir.

Anahtar sözcükler: Yozgat, yemek, tatl, kültür, yöre

\begin{abstract}
Yozgat is a city that both allows and gives a lot of immigrants. As it is allowing and giving a lot of immigrants, it is a matter of curiosity whether the people of Yozgat maintain their cultural values or not. The aim of this study is to reveal if the people of Yozgat know their food and dessert culture. The sample of the study consists of 50 women who are originally from Yozgat but some of them live there, some of them live in different cities in Turkey and some of them live abroad. During the creation of the data collection tool, a total of 8 questions consisting of 5 main and 3 sub-questions were prepared by getting the opinioins of 3 public educators. Thus, an interview form consisting of 8 questions was used in data colection. Through this interview form, by considering the age and working status variables, it has been revealed how much the women from Yozgat know about the food and dessert culture of Yozgat. In analyzing the obtained data, content analysis was used and the data were devided into certain categories and themes, shown as frequency and percentages, and various comparisons were made. The results of the study showed that the women between the ages of 46-70 know more about the food and dessert culture of Yozgat than women between the ages of 20-45. In addition to this, it was found out that the women who do not work know the food and dessert culture more than those who work.
\end{abstract}

Keywords: Yozgat, food, dessert, culture, region

\title{
Extended abstract
}

Yozgat, which is one of the cities of central Anatolia region, allowed immigrants both from other cities in Turkey such as Ankara, Kars, Erzurum, Nevşehir, Tokat and many other cities and also from other countries such as Bulgaria, Greece, Romania and some other. Yozgat also gave immigrants to some cities in Turkey such as Ankara, İstanbul, Kayseri, İzmir and some other cities and to some countries such as Germany, Austria, France, and Netherlands. As it is allowing and giving a lot of immigrants, it is a matter of curiosity whether the people of Yozgat maintain their cultural values or not. The purpose of this study is to reveal how much the women of Yozgat know and make their traditional food and desserts. Based on their demographic characteristics such as working status and age, it was examined how much the women of Yozgat know about the local food and dessert and whether they make these desserts and food or not.

The sample of the study consists of 50 women who are originally from Yozgat but some of them live there, some of them live in different cities in Turkey and some of them live abroad. While selecting the study group, it was paid attention to make an equal distribution; 25 women are 20-45 years old, 25 women are 46-70 years old, 25 women are working and 25 women are housewives. While selecting the participant women, convenience sampling was 
used which is one of the purposive sampling methods.

While creating the data collection tool, first of all an interview form was created which has 8 questions consisting of 6 main and 2 sub questions. Then, the opinions of 2 public educators were asked and in line with the common views of both researchers and public educators, 2 of the 6 main questions were excluded and a new main question was added, and a new sub question was added to the 2 sub questions. Thus, for the data collection, a 8 -questions interview form consisting of 5 main and 3 sub-questions was created.

In analysing the data, content analysis was used and the data were divided into certain categories and themes, shown as frequency and percentages, and various comparisons were made. Besides, in order to determine whether some data are correct or not, the information provided by Yozgat Governorate Provincial Directorate of Culture and Tourism on the internet about "Yozgat Cuisine and Local Food" was used.

When the findings obtained from the research are evaluated, it is possible to say the following: the women between the ages of 46-70 have more knowledge about the food and desserts of Yozgat than the women between the ages of 20-45.In addition, it was seen that the women who do not work have more knowledge about these desserts and food than the women who work. However, due to the immigration to Yozgat from Kars and Erzurum cities, an interaction occurred and because of this interaction the women in Yozgat adapted some traditional dishes from Kars such as "kesme aşı", "boz aşı soup", "haşıl" and "kete". Also, some traditional Erzurum dishes were adapted such as "hasita" and "kete".It was also revealed that the women of Yozgat were also affected by the culture of the provinces and added some other dishes to their own food culture, such as "düğürcük soup" from Amasya, "sündürme dish" from Çorum, "bat dish" from Tokat, and "ekmek aşı soup" from Sivas and Tokat. According to Düzgün and Özkaya (2014), migrations play an important role in determining food culture.

Considering the findings regarding the cooking the food and desserts that belong to Yozgat, it was found out that the women between the ages of 46-70 stated that they know the preparation and cooking of these dishes more than the other women who are at the ages of between 20-45. Also, it was found out that the women who do not work stated that they know how to cook these dishes more than the women who work. In order to prove the accuracy of the information given by the women, the recipes were asked from them and it was found out that the majority of the women between the ages of 46-70 gave many recipes correctly. However, only a few of the women between the ages of 20-45 gave the recipes correctly. Also, it was determined that the majority of the women who do not work and very few of the women who work gave these recipes correctly. Those who did not know how to cook and prepare these desserts and food were asked to write the ingredients that are used in these desserts and food, and a lot of women between the ages of 20-45 and several women between the ages of 46-70 answered this question. For this reason, it is seen that women in the age range of 20-45 gave more information than women in the age range of 46-70.It was also observed that the women who do not work know the ingredients used in these dishes and desserts with a little difference compared to those who work. Almost half of the women who are between the ages of 20-45 and the women who work stated that they cannot cook these dishes because they find the cooking of these dishes very troublesome. 
It has been revealed that the women between 46-70 years old give more place to the desserts and food of Yozgat in their homes compared to the women between 20-45 years old. The reasons that the women between the ages of 46-70 give a place to these local dishes in their homes are as follows: they find them very delicious, they think that these dishes are healthy, family members love these dishes, these dishes reflect their culture, and they adopt cultural dishes. Another result of the study revealed that the majority of the women who do not work and very few of the women who work give a place to Yozgat traditional food and desserts in their homes. In a study by Akkus (2019), which coincides with this finding, it was stated that as the time spent at home increases, the time allocated to these dishes also increases. Akkus also revealed that most of the women over middle age spend more time on meals as they do not work.

While most of the women between the ages of 20-45 say that the food and desserts of Yozgat region have been forgotten, many of the 46-70 year-olds have stated that the food and desserts of this region are not forgotten. While the majority of the women who work have the view that the Yozgat culture has been forgotten, most of the non-worker women have been seen to have the opposite view. The women between the ages of 46-70 think that Yozgat food and dessert culture has not been forgotten because they know how to cook them very well and keep this culture alive. On the other hand, the women who are between 20-45 years old and work think that this culture has been forgotten because they do not know how to cook these dishes and they cannot keep this culture alive.

In the study, various suggestions were also asked from the participants in order to prevent the oblivion of the food and dessert culture of Yozgat. The participants stated that they can introduce the food culture of Yozgat by using mass media, Yozgat food and desserts can be taught to the new generation, special events can be organized to introduce the food and desserts of this region, researches can be done about Yozgat, these food and desserts must be given more importance in homes, food and desserts of Yozgat can be sold, and some competitions related to food and dessert culture of Yozgat can be organized. In their research, Erdem, Mizrak and Kemer (2018) stated that the promotion of local dishes should be provided nationally and internationally, and they underlined that the promotions are inadequate. They also stated that in order to promote the local dishes, promotions should be made in fairs and competitions, training for local dishes should be made at schools, TV programs and social media should be used as promotional tools, and associations and municipalities should support this promotion. So, some overlapping findings can be seen with this study.

When the findings of this study are evaluated and summarized, it is seen that two important results stand out. The first is that the older generation (46-70 years old) are more dependent on the cultural values than the new generation (20-45 years old) and they keep the food and dessert culture alive. Also, the older generation have a wider knowledge on food and dessert culture. However, it is also noteworthy that many dishes and desserts of the Yozgat region were not mentioned at all. Among these, some traditional dishes can be mentioned, such as "çiğdem pilavı”, "yarma aşı", "yumurta tatlısı”, "mısır tatlısı”, “ekşili kabak”, "gınnıç”, "tene pilav”, etc. Therefore, it can be said that the food and dessert culture of Yozgat has begun to be forgotten. The second important result is that the women that do not work have a wider knowledge about food and dessert culture compared to the women who work and they try to keep this culture alive. 


\section{Giriş}

Yozgat, konum itibariyle İç Anadolu'nun Orta Kızılırmak bölümünde yer almaktadır. Doğuda Sivas, batıda Kırıkkale, kuzeyde Amasya, Çorum ve Tokat, güneyde Nevşehir ve Kayseri, güney batıda ise Kırşehir illeri bulunmaktadır.

Bir şehrin konumu ve ekonomisi yöresel yemeklerinin ve beslenme kültürünün şekillenmesinde önem arz etmektedir. (Serçeoğlu, 2014). Bir yörede yetiştirilen ürünler yöre halkının kültürüyle de bütünleşerek yöresel yemeklerin oluşmasına katkı sağlamış ve bu yöresel yemeklerin gelenekselleşerek nesilden nesile aktarılmasına yardımcı olmuştur. (Büyükşalvarc1, Şapcilar ve Yilmaz, 2016).

Yozgat ili Ankara, Kars, Erzurum, Nevşehir, Tokat vd. birçok ilden ve Bulgaristan, Yunanistan, Romanya vd. ülkelerden göç almış aynı zamanda Ankara, İstanbul, Kayseri, İzmir vd. bazı illere ve Almanya, Avusturya, Fransa, Hollanda vd. bazı ülkelere çok fazla göç vermiştir. (Yurt, 2016). Göç bir coğrafyadan diğerine yerleşen insanların yerleştikleri coğrafyaya getirdikleri ekonomik, psikolojik ve kültürel birleşenler bütünüdür (Çağlayan, 2011). Göç eden halkın yeme içme alışkanlıklarının yerleşilen yeni coğrafyayla paylaşımı ise göçün önemli kültürel sonuçlarındandır.

Yemekler toplumun gelenek ve görenekleri, kültürel boyutları ve refah durumları gibi faktörlere bağlı olarak, bir gelişim sürecinden geçmektedir. Bununla birlikte insanların göç etmesi ve yer değiştirmeleri yemek kültürünün belirlenmesinde önem teşkil etmektedir (Düzgün ve Özkaya, 2014).

Yozgat denince akla ilk gelen yöresel lezzetler; testi kebabı, tandır kebabı, arabaşı, çap çup mant1, ayva basması, çiğdem pilavı, bazlama, düğürcük çorbası, bulama çorbası, sakala sarkan çorba, katmer, c1zlak, helle çorbası, haside, erişte, topak çorba, sütlü kabak, patlıcan turşusu, incir uyutması, madımak, köfte aşı, gılik ve tas kebabıdır. Parmak çörek ve peksimet de Yozgat'a mahsus özel bir ekmek türüdür (Çelik, Aksoy ve Özkaya, 2017).

Yozgat ilinin bu kadar göç alması ve vermesi sebebiyle de Yozgat halkının kültürel değerlerini devam ettirip ettirmedikleri, yemek ve tatlı kültürünün unutup unutmadıkları ve bu yöreye göç eden halkın kültüründen etkilenip etkilenmedikleri merak konusudur.

Bu çalışmanın amacı da Yozgatlı kadınların geleneksel yemek ve tatlıları ne kadar bildiklerini ve yaptıklarını ortaya çıkarmaktır. Yozgatlı kadınların yöresel yemeklerle tatlılar hakkında ne kadar bilgi sahibi oldukları ve bu yemeklerle tatlıları yapıp yapmadıkları demografik özelliklerden olan çalışma ve yaş durumundan hareketle irdelenmiştir.

\section{Yöntem}

\section{Çalışma grubu}

Çalışma grubunu, aslen Yozgatlı olup da gerek Yozgatıta gerekse Türkiye`nin çeşitli illerinde ve yurtdışında yaşayan 50 kadın oluşturmaktadır. Kadınların seçimi esnasında eşit bir dağılımın yapılmasına dikkat edilmiş; 25 kişinin 20-45, 25 kişinin de 46-70 yaş aralığında ve 25 kadının çalışan, 25 kadının da ev hanımı olmasına dikkat edilmiştir. Yozgatlı kadınların seçimi sırasında amaçlı örnekleme yöntemlerinden olan kolay ulaşılabilir durum örneklemesinden faydalanılmıştır. 


\section{Verilerin toplanması}

Veri toplama aracının oluşturulmasında ilk önce, araştırmacılar tarafından 6 ana, 2 de alt sorudan oluşan toplam 8 soruluk bir görüşme formu oluşturulmuştur. Daha sonra da2halk eğitimcisinin görüşüne başvurulmuş; hem araştırmacılar hem de halk eğitimcilerinin ortak görüşleri doğrultusunda 6 ana sorudan2'si çıkarılmış ve yeni bir ana soru eklenmiş, 2 alt soruya da yeni bir alt soru dâhil edilmiştir.Böylece verilerin toplanması sırasında 5 ana, 3 de alt sorudan oluşan toplam 8 soruluk bir görüşme formu meydana getirilmiştir.

Görüşme formunda yer alan sorular şunlardır:

1. Yozgat yöresine ait hangi yemek ve tatlıları biliyorsunuz?

2. Yozgat yöresine ait yemek ve tatlıların yapılışını biliyor musunuz?

2.1. Cevabınız evet veya kısmen ise bu yemek ve tatlıların malzemelerini,tariflerini yazar misiniz?

2.2. Cevabınız hayır ise bu yemek ve tatlılarda kullanılan malzemeleri biliyorsanız yazar misiniz?

2.3. Cevabınız hayır veya kısmen ise bu yemek ve tatlıları yapamama nedenlerinizi yazar misinız?

3. Evinizde Yozgat yöresine ait yemek ve tatlılara yer veriyor musunuz? Neden?

4. Yozgat yöresi yemek ve tatlı kültürünün unutulduğunu düşünüyor musunuz? Neden?

5. Yozgat yöresi yemek ve tatlı kültürünün unutulmaması için neler önerirsiniz?

\section{Verilerin çözümlenmesi}

Araştırma verilerinin çözümlenmesinde içerik analizi kullanılmış; veriler belli kategorilerle temalara ayrılarak incelenmiş, frekans ve yüzdeliklerle gösterilmiştir. Ayrıca verilerin çözümlenmesi esnasında çeşitli karşılaştırmalarda yapılmıştır.Bunun yanında bazı verilerin doğru olup olmadığını tespit etmek amacıyla da T.C. Yozgat Valiliği İl Kültür ve Turizm Müdürlüğünün internet üzerinden yayınladığg "Yozgat Mutfağı ve Yöresel Yemekleri” ile ilgili vermiş olduğu bilgilerden yararlanılmış ve katılımcıların yanlış verdikleri bilgiler bulgulara dâhil edilmemiştir (T.C. Yozgat Valiliği İl Kültür ve Turizm Müdürlüğü).

\section{Bulgular}

Araştırmanın bulguları, görüşme formu aracılığıyla elde edilen sonuçlar neticesinde 5 ana ve 3 de alt başlık altında toplanmıştır.

\section{Yozgat yöresine ait hangi yemek ve tatlıları bildiklerine ilişkin bulgular}

Yozgat yöresine ait birçok yemek ve tatlı bulunmaktadır. Yozgatlı kadınların bu yemek ve tatlılardan hangilerini bildikleri araştırılmış ve elde edilen verilerden hareketle Tablo 1 ve Tablo 2 oluşturulmuştur. 
Tablo 1.

Katılımcıların yaş durumuna göre Yozgat yöresine ilişkin bildikleri yemeklerle tatlılara ait frekans ve yüzde dăğlımı

\begin{tabular}{|c|c|c|c|c|}
\hline \multirow{2}{*}{ Tema } & \multicolumn{2}{|c|}{ 20-45 Yaş } & \multicolumn{2}{|c|}{ 46-70 Yaş } \\
\hline & f & $\%$ & f & $\%$ \\
\hline Arabaşı & 14 & 56 & 20 & 80 \\
\hline Madımak & 12 & 48 & 18 & 72 \\
\hline Testi kebabı & 11 & 44 & 18 & 72 \\
\hline Sulu köfte/Köfte aşı & 8 & 32 & 19 & 76 \\
\hline İncir uyutması & 4 & 16 & 20 & 80 \\
\hline Çapçup mantı & 6 & 24 & 17 & 68 \\
\hline Tandır kebabı & 4 & 16 & 14 & 56 \\
\hline Sakala sarkan çorba/Kesme aşı çorbası & 3 & 12 & 14 & 56 \\
\hline Düğürcük çorbası & 2 & 8 & 14 & 56 \\
\hline Bulama çorbası & 1 & 4 & 15 & 60 \\
\hline Parmak çörek & 4 & 16 & 10 & 40 \\
\hline Gilik & 4 & 16 & 9 & 36 \\
\hline Omaç & 1 & 4 & 11 & 44 \\
\hline Helle/Herle çorbası & 3 & 12 & 8 & 32 \\
\hline Hingel/Hengel & 1 & 4 & 9 & 36 \\
\hline Hasita/Hasuta/Gebil & 1 & 4 & 9 & 36 \\
\hline Cilbir & 2 & 8 & 6 & 24 \\
\hline Sütlü çorba & 1 & 4 & 6 & 24 \\
\hline Bazlama & 1 & 4 & 5 & 20 \\
\hline Sini & 0 & 0 & 6 & 24 \\
\hline Hedik & 2 & 8 & 4 & 16 \\
\hline Mihla & 0 & 0 & 4 & 16 \\
\hline Haşıl & 0 & 0 & 3 & 12 \\
\hline Mihlama & 0 & 0 & 3 & 12 \\
\hline Bat yemeği & 0 & 0 & 3 & 12 \\
\hline Ekmek aş1 çorbası & 2 & 8 & 0 & 0 \\
\hline Kete & 0 & 0 & 2 & 8 \\
\hline Boz aşı çorbası & 0 & 0 & 2 & 8 \\
\hline Sündürme & 1 & 4 & 0 & 0 \\
\hline
\end{tabular}

Tablo 1'e bakıldığı zaman, 46-70 yaş aralığındaki kadınların 20-45 yaş aralığındakilere göre Yozgat yemek ve tatlılarını çok daha iyi bildikleri görülmektedir. Katılımcıların arabaşı, madımak, testi kebabı, sulu köfte/köfte aşı, incir uyutması, çapçup mantı, tandır kebabı, sakala sarkan çorba/kesme aşı çorbası, düğürcük çorbası, bulama çorbası, parmak çörek, gilik, omaç, helle/herle çorbası, hingel/hengel, hasıta/hasuta/gebil, cılbır, sütlü çorba, bazlama, sini, hedik, mıhla, haşı1, mıhlama, bat yemeği, ekmek aşı çorbası, kete, boz aşı çorbası ve sündürme gibi yemek ve tatlıların Yozgat yöresine ait olduğunu dile getirdikleri tespit edilmiştir. 46-70 yaş arasındaki kadınların çoğu 27, 20-45 yaş arasındaki kadınların ise bazıları 22 yemekten söz etmişlerdir.

Araştırma esnasında katılımcıların çalışıp çalışmama durumları da dikkate alınmış ve bu durumun katılımcıların Yozgat yöresi yemek ve tatlılarına ilişkin bilgilerini etkileyip etkilemediğine Tablo 2'de yer verilmiştir. 
Tablo 2.

Katılımcıların çalışıp çalışmama durumuna göre Yozgat yöresine ilişkin bildikleri yemeklerle tatlılara ait frekans ve yüzde dağılımı

\begin{tabular}{|c|c|c|c|c|}
\hline \multirow{2}{*}{ Tema } & \multicolumn{2}{|c|}{ Çalışanlar } & \multicolumn{2}{|c|}{ Çalışmayanlar } \\
\hline & f & $\%$ & $\mathbf{f}$ & $\%$ \\
\hline Arabaşı & 10 & 40 & 24 & 96 \\
\hline Madımak & 7 & 28 & 23 & 92 \\
\hline Testi kebabı & 7 & 28 & 22 & 88 \\
\hline Sulu köfte/Köfte aşı & 4 & 16 & 23 & 92 \\
\hline İncir uyutması & 6 & 24 & 18 & 72 \\
\hline Çapçup mantı & 4 & 16 & 19 & 76 \\
\hline Tandir kebabı & 7 & 28 & 11 & 44 \\
\hline Sakala sarkan çorba/Kesme aşı çorbası & 4 & 16 & 13 & 52 \\
\hline Düğürcük çorbası & 2 & 8 & 14 & 56 \\
\hline Bulama çorbası & 4 & 16 & 12 & 48 \\
\hline Parmak çörek & 6 & 24 & 8 & 32 \\
\hline Gilik & 2 & 8 & 11 & 44 \\
\hline Omaç & 2 & 8 & 10 & 40 \\
\hline Helle/Herle çorbası & 2 & 8 & 9 & 36 \\
\hline Hingel/Hengel & 2 & 8 & 8 & 32 \\
\hline Hasita/Hasuta/Gebil & 1 & 4 & 9 & 36 \\
\hline Cilbir & 1 & 4 & 7 & 28 \\
\hline Sütlü çorba & 2 & 8 & 5 & 20 \\
\hline Bazlama & 0 & 0 & 6 & 24 \\
\hline Sini & 0 & 0 & 6 & 24 \\
\hline Hedik & 1 & 4 & 5 & 20 \\
\hline Mihla & 0 & 0 & 4 & 16 \\
\hline Haşı1 & 0 & 0 & 3 & 12 \\
\hline Mihlama & 1 & 4 & 2 & 8 \\
\hline Bat yemeği & 0 & 0 & 3 & 12 \\
\hline Ekmek aşı çorbası & 1 & 4 & 1 & 4 \\
\hline Kete & 0 & 0 & 2 & 8 \\
\hline Boz aşı çorbası & 0 & 0 & 2 & 8 \\
\hline Sündürme & 0 & 0 & 1 & 4 \\
\hline
\end{tabular}

Tablo 2'ye göre çalışmayan kadınların çalışan kadınlara kıyasla Yozgat yöresi yemek ve tatlılarını çok daha fazla bildikleri ortaya çıkmıştır. Çalışmayanlar 29, çalışanlar da 21 yemekten bahsetmişlerdir.

2. Yozgat yöresine ait yemeklerle tatlıların yapılışını bilip bilmediklerine ilişkin bulgular

Araştırmada Yozgatlı kadınların, Yozgat'a ait yemek ve tatlıların yapılışını bilip bilmediklerine ilişkin veriler de toplanarak Tablo 3 ve Tablo 4 oluşturulmuştur. 
Tablo 3 .

Katılımcıların yaş durumuna göre Yozgat yöresine ait yemeklerle tatlıların yapılışını bilip bilmediklerine ait frekans ve yüzde dağılımı

\begin{tabular}{|l|c|c|c|c|}
\hline \multirow{2}{*}{ Kategori } & \multicolumn{2}{c|}{$\mathbf{2 0 - 4 5}$ Yaş } & \multicolumn{2}{c|}{ 46-70 Yaş } \\
\cline { 2 - 5 } & f & \% & f & \% \\
\hline Evet, biliyorum. & 6 & 24 & 18 & 72 \\
Kismen biliyorum. & 4 & 16 & 6 & 24 \\
Hayır, bilmiyorum. & 15 & 60 & 1 & 4 \\
\hline
\end{tabular}

Tablo 3 incelendiği zaman, yaşları 46-70 arasında olan Yozgatlı kadınların \%72'sinin, yaşları 20-45 arasında olanların ise \%24'ünün Yozgat yöresine ait yemeklerle tatlıların yapılışını bildiklerini dile getirdikleri görülmüştür.

Araştırmada, Yozgatlı kadınların bu yemek ve tatlıların yapılışını bilip bilmedikleri çalışma durumuna göre ele alınmış ve Tablo 4 meydana getirilmiştir.

Tablo 4.

Katılımcıların çalışıp çalışmama durumuna göre Yozgat yöresine ait yemeklerle tatlıların yapılışını bilip bilmediklerine ait frekans ve yüzde dă̆ılımı

\begin{tabular}{|l|c|c|c|c|}
\hline \multirow{2}{*}{\multicolumn{1}{c|}{ Kategori }} & \multicolumn{2}{c|}{ Çalışanlar } & \multicolumn{2}{c|}{ Çalışmayanlar } \\
\cline { 2 - 5 } & f & \% & f & \% \\
\hline Evet, biliyorum. & 4 & 16 & 20 & 80 \\
Kısmen biliyorum. & 5 & 20 & 5 & 20 \\
Hayır, bilmiyorum. & 16 & 64 & 0 & 0 \\
\hline
\end{tabular}

Tablo 4'te de görüldüğü gibi, çalışmayanların \%80'i, çalışanların da \%16’sı Yozgat yöresine ait yemeklerle tatlıların yapılışını bildiklerini söylemişlerdir.

2.1.Yozgat yöresine ait yemeklerle tatlıların yapılışını bilenlerin bu yemek ve tatlıların malzemeleri ile tariflerine ilişkin görüşleri

Yozgat yöresine ait yemeklerle tatlıların tarif ve malzemelerini doğru bilenlerin verdikleri görüşler doğrultusunda Tablo 5 ve Tablo 6 oluşturulmuştur. 
Tablo 5.

Katılımcıların yaş durumuna göre Yozgat yöresine ait hangi yemek ve tatlıların malzemeleri ile tariflerini bildiklerine ilişkin frekans ve yüzde dağılımı

\begin{tabular}{|c|c|c|c|c|}
\hline \multirow{2}{*}{ Tema } & \multicolumn{2}{|c|}{ 20-45 Yaş } & \multicolumn{2}{|c|}{ 46-70 Yaş } \\
\hline & f & $\%$ & f & $\%$ \\
\hline Arabaşı & 5 & 20 & 21 & 84 \\
\hline Madımak & 3 & 12 & 15 & 60 \\
\hline Çapçup mantı & 0 & 0 & 16 & 64 \\
\hline Sulu köfte/Köfte aşı & 2 & 8 & 14 & 56 \\
\hline İncir uyutması & 0 & 0 & 11 & 44 \\
\hline Testi kebab1 & 1 & 4 & 9 & 36 \\
\hline Tandır kebabı & 0 & 0 & 10 & 40 \\
\hline Gilik & 2 & 8 & 8 & 32 \\
\hline Hingel/Hengel & 0 & 0 & 8 & 32 \\
\hline Düğürcük çorbası & 0 & 0 & 7 & 28 \\
\hline Omaç & 0 & 0 & 7 & 28 \\
\hline Helle çorbası & 1 & 4 & 6 & 24 \\
\hline Parmak çörek & 0 & 0 & 6 & 24 \\
\hline Hasita/Hasuta/Gebil & 2 & 8 & 4 & 16 \\
\hline Sakala sarkan çorba/Kesme aşı çorbası & 0 & 0 & 5 & 20 \\
\hline Sütlü çorba & 0 & 0 & 5 & 20 \\
\hline Bulama çorbası & 1 & 4 & 3 & 12 \\
\hline Haşı1 & 0 & 0 & 3 & 12 \\
\hline Cilbir & 0 & 0 & 2 & 8 \\
\hline Bat yemeği & 0 & 0 & 2 & 8 \\
\hline Sini & 0 & 0 & 2 & 8 \\
\hline Mihla & 0 & 0 & 1 & 4 \\
\hline
\end{tabular}

Tablo 5'e bakıldığında, 46-70 yaş arasındaki katılımcıların birçoğunun 22 yemeğe ilişkin doğru tarif verdikleri ancak 20-45 yaş arasındakilerin ise birkaçının 8 yemeğe ilişkin doğru tarif verdikleri ortaya çıkmıştır.

Araştırmada, bu yemek ve tatlıların malzemeleri ile tariflerini doğru bilmelerinin kadınların çalışma durumuna göre bir farklılık oluşturup oluşturmadığı da incelenmiş ve elde edilen bulgulara Tablo 6'dayer verilmiştir. 
Tablo 6.

Katılımcıların çalışıp çalışmama durumuna göre Yozgat yöresine ait hangi yemek ve tatlıların malzemeleri ile tariflerini bildiklerine ilişkin frekans ve yüzde dağılımı

\begin{tabular}{|c|c|c|c|c|}
\hline \multirow{2}{*}{ Tema } & \multicolumn{2}{|c|}{ Çalışanlar } & \multicolumn{2}{|c|}{ Çalışmayanlar } \\
\hline & f & $\%$ & f & $\%$ \\
\hline Arabaşı & 6 & 24 & 20 & 80 \\
\hline Madımak & 6 & 24 & 12 & 48 \\
\hline Çapçup mantı & 1 & 4 & 15 & 60 \\
\hline Sulu köfte/Köfte aş1 & 3 & 12 & 13 & 52 \\
\hline İncir uyutması & 2 & 8 & 9 & 36 \\
\hline Testi kebabı & 1 & 4 & 9 & 36 \\
\hline Tandır kebabı & 0 & 0 & 10 & 40 \\
\hline Gilik & 2 & 8 & 8 & 32 \\
\hline Hingel/Hengel & 2 & 8 & 6 & 24 \\
\hline Düğürcük çorbası & 1 & 4 & 6 & 24 \\
\hline Omaç & 0 & 0 & 7 & 28 \\
\hline Helle çorbası & 2 & 8 & 5 & 20 \\
\hline Parmak çörek & 1 & 4 & 5 & 20 \\
\hline Hasita/Hasuta/Gebil & 1 & 4 & 5 & 20 \\
\hline Sakala sarkan çorba/Kesme aşı çorbası & 0 & 0 & 5 & 20 \\
\hline Sütlü çorba & 1 & 4 & 4 & 16 \\
\hline Bulama çorbası & 0 & 0 & 4 & 16 \\
\hline Haşı1 & 1 & 4 & 2 & 8 \\
\hline Cilbir & 1 & 4 & 1 & 4 \\
\hline Bat yemeği & 1 & 4 & 1 & 4 \\
\hline Sini & 0 & 0 & 2 & 8 \\
\hline Mihla & 0 & 0 & 1 & 4 \\
\hline
\end{tabular}

Tablo 6'da, çalışmayan kadınların çoğunluğunun 22 yemek, çalışanların ise çok azının 16 yemek tarifini doğru verdikleri tespit edilmiştir.

2.2. Yozgat yöresine ait yemeklerle tatlıların yapılışını bilmeyenlerin bu yemek ve tatlılarda kullanılan malzemelere ilişkin görüşleri

Yöresel Yozgat yemek ve tatlılarının yapılışı esnasında birçok malzeme (madımak, mercimek, bulgur vs.) kullanılmaktadır. Bazı katılımcıların bu yemek ve tatlıların yapılışını bilmemelerine rağmen bu yemek ve tatlılarda kullanılan malzemeleri doğru bilip bilmedikleri de araştırılmış ve elde edilen veriler Tablo 7 ve Tablo 8'de sunulmuştur. 
Tablo 7.

Katılımcıların yaş durumuna göre Yozgat yöresine ait yemeklerle tatlıları bilmeyenlerin bu yemek ve tatlılarda kullanılan malzemelere ilişkin frekans ve yüzde dağılımı

\begin{tabular}{|l|c|c|c|c|}
\hline \multirow{2}{*}{ Tema } & \multicolumn{2}{c|}{$\mathbf{2 0 - 4 5}$ Yaş } & \multicolumn{2}{c|}{ 46-70 Yaş } \\
\cline { 2 - 5 } & f & \% & f & \% \\
\hline Arabaş1 & 6 & 24 & 1 & 4 \\
Madımak & 6 & 24 & 1 & 4 \\
Çapçup mantı & 5 & 20 & 1 & 4 \\
Sulu köfte/Köfte aş1 & 4 & 16 & 1 & 4 \\
İncir uyutması & 2 & 8 & 0 & 0 \\
Testi kebab1 & 1 & 4 & 1 & 4 \\
Gilik & 1 & 4 & 1 & 4 \\
Hingel/Hengel & 0 & 0 & 1 & 4 \\
\hline
\end{tabular}

Yöresel Yozgat yemek ve tatlılarının yapılışını bilmeyip de bu yemek ve tatlılarda kullanılan malzemeleri 20-45 yaş aralığındaki kadınların 46-70 yaş aralığındaki kadınlara göre daha fazla bilgi verdikleri Tablo 7'de açık bir şekilde görülmektedir.

Araştırma esnasında çalışanlar ile çalışmayanların bu yemek ve tatlıların yapılışında kullanılan malzemeleri bilip bilmediklerine de bakılmış ve Tablo 8 oluşturulmuştur.

Tablo 8 .

Katılımcıların çalışıp çalışmama durumuna göre Yozgat yöresine ait yemeklerle tatlıları bilmeyenlerin bu yemek ve tatlılarda kullanılan malzemelere ilişkin frekans ve yüzde dağılımı

\begin{tabular}{|l|c|c|c|c|}
\hline \multirow{2}{*}{ Tema } & \multicolumn{2}{c|}{ Çalışanlar } & \multicolumn{2}{c|}{ Çalışmayanlar } \\
\cline { 2 - 5 } & f & \% & f & $\%$ \\
\hline Arabaşı & 3 & 12 & 4 & 16 \\
Madımak & 2 & 8 & 5 & 20 \\
Çapçup mantı & 2 & 8 & 4 & 16 \\
Sulu köfte/Köfte aş1 & 3 & 12 & 2 & 8 \\
İncir uyutması & 1 & 4 & 1 & 4 \\
Testi kebab1 & 0 & 0 & 2 & 8 \\
Gilik & 1 & 4 & 1 & 4 \\
Hingel/Hengel & 0 & 0 & 1 & 4 \\
\hline
\end{tabular}

Tablo 8'de de görüldüğü gibi çalışmayanların çalışanlara göre çok az bir farkla bu yemek ve tatlılarda kullanılan malzemeleri daha iyi bildiklerine rastlanılmıştır. 
2.3. Yozgat yöresine ait yemeklerle tatlıların yapılışını hiç bilmeyenlerin veya kısmen bilenlerin bu yemeklerle tatlıları yapamama nedenlerine ilişkin görüşleri

Her yörenin kendine has yemek ve tatlıları vardır ve genellikle de bu yemek ve tatlılar yöre halkı tarafından da sıklıkla yapılmaktadır. Ancak Yozgatlı olup da bu yöreye ait yemek ve tatlıların yapılışını hâlen bilmeyenlerden ya da kısmen bilenlerden yöresel yemekleri yapamama nedenleri araştırılmış ve bu nedenler Tablo 9 ve Tablo 10' da ele alınmıştır.

Tablo 9.

Katılımcıların yaş durumuna göre Yozgat yöresine ait yemeklerle tatlıların yapılışını hiç bilmeyenlerin veya kısmen bilenlerin bu yemeklerle tatllarl yapamama nedenlerine ilişkin frekans ve yüzde dă̆ılımı

\begin{tabular}{|l|c|c|c|c|}
\hline \multirow{2}{*}{ Kategori } & \multicolumn{3}{c|}{$\mathbf{2 0 - 4 5}$ Yaş } & \multicolumn{2}{|c|}{$\mathbf{4 6 - 7 0}$ Yaş } \\
\cline { 2 - 5 } & $\mathbf{f}$ & $\mathbf{\%}$ & $\mathbf{f}$ & $\mathbf{\%}$ \\
\hline Yemek ve tatlıların oldukça zahmetli olması & 12 & 48 & 1 & 4 \\
Yemek ve tatlıların yapılışının bilinmemesi & 8 & 32 & 0 & 0 \\
Yemek ve tatlılara konan bazı malzemelerin temin edilememesi & 7 & 28 & 0 & 0 \\
Yemek ve tatlıların yapılışının çok vakit alması & 5 & 20 & 1 & 4 \\
Yemek ve tatlıların yapımında kullanılan araç ve gereç eksikliği & 3 & 12 & 0 & 0 \\
\hline
\end{tabular}

Genellikle 20-45 yaş aralığındaki Yozgatlı kadınlar, bu yemek ve tatlıları yapamadıklarını dile getirmişlerdi. Bundan ötürü 20-45 yaş aralığındaki kişilerin görüşlerine burada daha çok yer verilmiştir.Tablo 9'a da bakıldığında Yozgatlı kadınların bu yemek ve tatlıları yapamama sebepleri görülebilir: Yemek ve tatlıların oldukça zahmetli olması, yemek ve tatlıların yapılışının bilinmemesi, yemek ve tatlılara konan bazı malzemelerin temin edilememesi, yemek ve tatlıların yapılışının çok vakit alması, yemek ve tatlıların yapımında kullanılan araç ve gereç eksikliği.20-45 yaş aralığındaki kadınların neredeyse yarısı bu yemekleri oldukça zahmetli bulduklarını aktarmışlardır.

Yozgatlı kadınların yöresel yemek ve tatlıları yapamama nedenleri çalışma durumuna göre de değerlendirilmiş ve Tablo 10 meydana getirilmiştir.

Tablo 10.

Katılımcıların çalışıp çalışmama durumuna göre Yozgat yöresine ait yemeklerle tatlıların yapılışını hiç bilmeyenlerin veya kısmen bilenlerin bu yemeklerle tatlıları yapamama nedenlerine ilişkin frekans ve yüzde dă̆llımı

\begin{tabular}{|l|c|c|c|c|}
\hline \multirow{2}{*}{ Kategori } & \multicolumn{2}{|c|}{ Çalışanlar } & \multicolumn{2}{c|}{ Çalışmayanlar } \\
\cline { 2 - 5 } & $\mathbf{f}$ & $\mathbf{0}$ & $\mathbf{f}$ & $\mathbf{\%}$ \\
\hline Yemek ve tatlıların oldukça zahmetli olması & 11 & 44 & 2 & 8 \\
Yemek ve tatlıların yapılışının bilinmemesi & 8 & 32 & 0 & 0 \\
Yemek ve tatlılara konan bazı malzemelerin temin edilememesi & 2 & 8 & 5 & 20 \\
Yemek ve tatlıların yapılışının çok vakit alması & 5 & 20 & 1 & 4 \\
Yemek ve tatlıların yapımında kullanılan araç ve gereç eksikliği & 2 & 8 & 1 & 4 \\
\hline
\end{tabular}


Tablo 10'da,çalışanların büyük çoğunluğu (\%44) yemek ve tatlıların oldukça zahmetli olduğunu, çalışmayanların çoğu da (\%20) yemek ve tatlılara konan bazı malzemelerin temin edilemediğini yöresel yemekleri yapamama nedenleri olarak göstermişlerdir.

\section{Yozgat yöresine ait yemeklerle tatlılara evlerinde yer verip vermediklerine ve} bunların nedenlerine ilişkin bulgular

Yozgatlı kadınların yöresel Yozgat yemeklerine evlerinde yer verip vermedikleri ve bunların nedenleri araştırılmış, böylece Tablo 11 ve Tablo 12 oluşturulmuştur.

Tablo 11

Katılımcıların yaş durumuna göre Yozgat yöresine ait yemeklerle tatllara evlerinde yer verip vermediklerine ve bunların nedenlerine ilişkin frekans ve yüzde dağllımı

\begin{tabular}{|c|c|c|c|c|c|}
\hline \multirow{2}{*}{ Kategori } & \multirow{2}{*}{ Tema } & \multicolumn{2}{|c|}{ 20-45 Yaş } & \multicolumn{2}{|c|}{ 46-70 Yaş } \\
\hline & & f & $\%$ & f & $\%$ \\
\hline $\begin{array}{l}\text { Evet, yer } \\
\text { veriyorum. }\end{array}$ & $\begin{array}{l}\text { Lezzetli bulduklarından } \\
\text { Sağlıklı yemekler olduğundan } \\
\text { Ailedeki kişiler sevdiğinden } \\
\text { Damak tatlarına uygun olduğundan } \\
\text { Kültürlerini yansıttığından } \\
\text { Kültürel yemeklerin benimsenmesinden }\end{array}$ & 5 & 20 & 22 & 88 \\
\hline $\begin{array}{l}\text { Kismen yer } \\
\text { veriyorum. }\end{array}$ & $\begin{array}{l}\text { Damak tadına hitap etmemesinden } \\
\text { Mevsimlik yemekler olmasından } \\
\text { Zahmetli yemekler olduğundan }\end{array}$ & 4 & 16 & 2 & 8 \\
\hline $\begin{array}{l}\text { Hayır, yer } \\
\text { vermiyorum. }\end{array}$ & $\begin{array}{l}\text { Damak tadına hitap etmemesinden } \\
\text { Genellikle aile büyüklerinde yenildiğinden } \\
\text { Yemekleri yapacak vakit bulamamasından } \\
\text { Yemeklerin yapılışının bilinmemesinden } \\
\text { Zahmetli yemekler olmasından } \\
\text { Aile fertlerinin sevmemesinden } \\
\text { Malzeme eksikliğinden } \\
\text { Bazı restoranlarda bu yemekler olduğundan }\end{array}$ & 16 & 64 & 1 & 4 \\
\hline
\end{tabular}

Tablo 11 'de, 46-70 yaş aralığındaki kadınların \%88'inin, 20-45 yaş aralığındakilerin ise \%20'sinin evlerinde Yozgat yöresine ait yemeklerle tatlllara yer verdikleri görülmektedir. Bunun nedenlerini ise şu şekilde aktarmaktadırlar: Lezzetli bulduklarından, sağlıklı yemekler olduğundan, ailedeki kişiler sevdiğinden, damak tatlarına uygun olduğundan, kültürlerini yansıttığından, kültürel yemeklerin benimsenmesinden. Aynı zamanda 20-45 yaş aralığındakilerin \%64'ü, 46-70 yaş aralığındaki kadınların ise \%4'ü evlerinde Yozgat yöresine ait yemeklerle tatlılara yer vermediklerini dile getirmişlerdir. Yöresel yemeklere evlerinde yer vermeme nedenlerini ise şu şekilde izah etmektedirler: Damak tadına hitap etmemesinden, genellikle aile büyüklerinde yenildiğinden, yemekleri yapacak vakit bulamamasından, ye- 
meklerin yapılışının bilinmemesinden, zahmetli yemekler olmasından, aile fertlerinin sevmemesinden, malzeme eksikliğinden, bazı restoranlarda bu yemekler olduğundan.

Yozgatlı kadınların, yöresel yemeklerle tatlılara evlerinde yer verip vermedikleri çalışma durumundan hareketle incelenmiş ve elde edilen veriler Tablo 12'de verilmiştir.

Tablo 12.

Katılımcıların çalışıp çalışmama durumuna göre Yozgat yöresine ait yemeklerle tatllara evlerinde yer verip vermediklerine ve bunların nedenlerine ilişkin frekans ve yüzde dă̆llımı

\begin{tabular}{|c|c|c|c|c|c|}
\hline \multirow{2}{*}{ Kategori } & \multirow{2}{*}{ Tema } & \multicolumn{2}{|c|}{ Çalışanlar } & \multicolumn{2}{|c|}{ Çalışmayanlar } \\
\hline & & f & $\%$ & f & $\%$ \\
\hline \multirow{6}{*}{$\begin{array}{l}\text { Evet, yer } \\
\text { veriyorum. }\end{array}$} & Lezzetli bulduklarından & \multirow{6}{*}{4} & \multirow{6}{*}{16} & \multirow{6}{*}{23} & \multirow{6}{*}{92} \\
\hline & Sağlıklı yemekler olduğundan & & & & \\
\hline & Ailedeki kişiler sevdiğinden & & & & \\
\hline & Damak tatlarına uygun olduğundan & & & & \\
\hline & Kültürlerini yansıttığından & & & & \\
\hline & Kültürel yemeklerin benimsenmesinden & & & & \\
\hline \multirow{3}{*}{$\begin{array}{l}\text { Kismen yer } \\
\text { veriyorum. }\end{array}$} & Damak tadına hitap etmemesinden & \multirow{3}{*}{4} & \multirow{3}{*}{16} & \multirow{3}{*}{2} & \multirow{3}{*}{8} \\
\hline & Mevsimlik yemekler olmasından & & & & \\
\hline & Zahmetli yemekler olduğundan & & & & \\
\hline \multirow{8}{*}{$\begin{array}{l}\text { Hayır, yer } \\
\text { vermiyorum. }\end{array}$} & Damak tadına hitap etmemesinden & \multirow{8}{*}{17} & \multirow{8}{*}{68} & \multirow{8}{*}{0} & \multirow{8}{*}{0} \\
\hline & Genellikle aile büyüklerinde yenildiğinden & & & & \\
\hline & Yemekleri yapacak vakit bulamamasından & & & & \\
\hline & Yemeklerin yapılışının bilinmemesinden & & & & \\
\hline & Zahmetli yemekler olmasindan & & & & \\
\hline & Aile fertlerinin sevmemesinden & & & & \\
\hline & Malzeme eksikliğinden & & & & \\
\hline & Bazı restoranlarda bu yemekler olduğundan & & & & \\
\hline
\end{tabular}

Tablo 12'de de görülüyor ki, çalışmayan kadınların büyük çoğunluğu (\%92), çalışan kadınların ise çok azı (\%16) evlerinde Yozgat yöresine ait yemeklerle tatlılara yer vermektedirler.

\section{Yozgat yöresi yemekleriyle tatlılarının unutulup unutulmadığına ve bunların ne- denlerine ilişkin bulgular}

Yozgat yöresi yemekleriyle tatlılarının unutulup unutulmadığı ve bunların nedenleri Yozgatlı kadınların görüşleri aracılığıyla belirlenmiştir. Buna ilişkin bulgular Tablo 13 ve Tablo 14'tesunulmuştur. 


\begin{tabular}{|c|c|c|c|c|c|}
\hline $\begin{array}{l}\text { Tablo } 13 . \\
\text { Katılımcılar } \\
\text { unutulmadıg }\end{array}$ & $\begin{array}{l}\text { yaş durumuna göre Yozgat yöresi yemekler } \\
\text { a ve bunların nedenlerine ilişkin frekans ve yüzde }\end{array}$ & & & & \\
\hline & & 20 & Yaş & $46-7$ & Yaş \\
\hline Kategori & Tema & f & $\%$ & $\mathbf{f}$ & $\%$ \\
\hline $\begin{array}{l}\text { Evet, } \\
\text { unutuldu. }\end{array}$ & $\begin{array}{l}\text { Yapılışlarının zahmetli olmasından } \\
\text { Lezzetli yemekler olmamasından } \\
\text { Pratik yermekler olmamasından } \\
\text { Et ağırlıklı olmasından } \\
\text { Hamur işinden uzak durulmasından } \\
\text { Çoğu kişinin sebze ağırlıklı yemekleri tercih } \\
\text { etmesinden } \\
\text { Genç neslin daha çok fast food tercih etmesinden } \\
\text { Çalışanların çoğunlukla dışarıda yemek yemesinden } \\
\text { Yeni neslin bu yemekleri bilmemesinden ve } \\
\text { yapamamasından } \\
\text { Yozgat'a başka illerden göç edenlerin kültürlerinden } \\
\text { etkilenilmesinden } \\
\text { Kolay yapılan yemeklerin daha çok tercih edilmesinden } \\
\text { Bu yemeklerin evlerde sıklıkla pişirilmemesinden } \\
\text { Genç neslin bu yemekleri sevmemesinden }\end{array}$ & 23 & 92 & 5 & 20 \\
\hline $\begin{array}{l}\text { Hayır, } \\
\text { unutulmadi. }\end{array}$ & $\begin{array}{l}\text { Aile büyüklerinin bu yemekleri hâlen yapmalarından } \\
\text { Damak tadına hitap etmesinden } \\
\text { Gelenek ve göreneklerine bağlı olan herkes yaptığından } \\
\text { Evlerde sık sık bu yemeklere yer verildiğinden } \\
\text { Aile fertlerinin severek yemesinden } \\
\text { Alışkanlıklardan kolay kolay vazgeçilmediğinden } \\
\text { Bazı restoranlarda bu yemekler bulunduğundan } \\
\text { Lezzetli yemekler olduğundan } \\
\text { Sağlıklı yemekler olduğundan } \\
\text { Yozgat'taki önemli günlerde bu yemek ve tatlılara yer } \\
\text { verildiğinden }\end{array}$ & 2 & 8 & 20 & 80 \\
\hline
\end{tabular}

20-45 yaş aralığındaki kadınların \%92'si Yozgat yöresi yemek ve tatlılarının unutulduğu, 46-70 yaş aralığındakilerin \%80'i ise bu yöreye ait yemek ve tatlıların unutulmadığı görüşündedir. Bu kültürün unutulma nedenlerini şöyle aktarmışlardır: Yapılışlarının zahmetli olması, lezzetli yemekler olmaması, pratik yermekler olmaması, et ağırlıklı olması, hamur işinden uzak durulması, çoğu kişinin sebze ağırlıklı yemekleri tercih etmesi,genç neslin daha çok fast food tercih etmesi, çalışanların çoğunlukla dışarıda yemek yemesi, yeni neslin bu yemekleri bilmemesi ve yapamaması, Yozgat'a başka illerden göç edenlerin kültürlerinden etkilenilmesi, kolay yapılan yemeklerin daha çok tercih edilmesi, bu yemeklerin evlerde sıklıkla pişirilmemesi, genç neslin bu yemekleri sevmemesi. Bu kültürün unutulmama nedenlerini ise şöyle sıralamak mümkündür: Aile büyüklerinin bu yemekleri hâlen yapmaları, damak tadına hitap 
etmesi, gelenek ve göreneklerine bağlı olan herkesin yapması, evlerde sık sık bu yemeklere yer verilmesi, aile fertlerinin severek yemesi, alışkanlıklardan kolay kolay vazgeçilmemesi, bazı restoranlarda bu yemeklerin bulunması, lezzetli yemekler olması, sağlıklı yemekler olması, Yozgat'taki önemli günlerde bu yemek ve tatlılara yer verilmesi.

Yozgatlı kadınların çalışma durumları da göz önünde bulundurularak yöresel yemeklerle tatlıların unutulup unutulmadığına bakılmış ve elde edilen bulgulara Tablo 14'te yer verilmiştir.

Tablo 14.

Katılımcıların çalışıp çalışmama durumuna göre Yozgat yöresi yemekleriyle tatlllarının unutulup unutulmadı̆̆ına ve bunların nedenlerine ilişkin frekans ve yüzde dă̆ılımı

\begin{tabular}{|c|c|c|c|c|c|}
\hline \multirow{2}{*}{ Kategori } & \multirow{2}{*}{ Tema } & \multicolumn{2}{|c|}{ Çalışanlar } & \multicolumn{2}{|c|}{ Çalışmayanlar } \\
\hline & & f & $\%$ & f & $\%$ \\
\hline $\begin{array}{l}\text { Evet, } \\
\text { unutuldu. }\end{array}$ & $\begin{array}{l}\text { Yapılışlarının zahmetli olmasından } \\
\text { Lezzetli yemekler olmamasından } \\
\text { Pratik yermekler olmamasından } \\
\text { Et ağıllıklı olmasından } \\
\text { Hamur işinden uzak durulmasından } \\
\text { Çoğu kişinin sebze ağırlıklı yemekleri tercih } \\
\text { etmesinden } \\
\text { Genç neslin daha çok fast food tercih etmesinden } \\
\text { Çalışanların çoğunlukla dışarıda yemek } \\
\text { yemesinden } \\
\text { Yeni neslin bu yemekleri bilmemesinden ve } \\
\text { yapamamasından } \\
\text { Yozgat'a başka illerden göç edenlerin } \\
\text { kültürlerinden etkilenilmesinden } \\
\text { Kolay yapılan yemeklerin daha çok tercih } \\
\text { edilmesinden } \\
\text { Bu yemeklerin evlerde sıklıkla pişirilmemesinden } \\
\text { Genç neslin bu yemekleri sevmemesinden }\end{array}$ & 20 & 80 & 8 & 32 \\
\hline $\begin{array}{l}\text { Hayır, } \\
\text { unutulmadı. }\end{array}$ & $\begin{array}{l}\text { Aile büyüklerinin bu yemekleri hâlen } \\
\text { yapmalarından } \\
\text { Damak tadına hitap etmesinden } \\
\text { Gelenek ve göreneklerine bağlı olan herkes } \\
\text { yaptığından } \\
\text { Evlerde sık sık bu yemeklere yer verildiğinden } \\
\text { Aile fertlerinin severek yemesinden } \\
\text { Alışkanlıklardan kolay kolay vazgeçilmediğinden } \\
\text { Bazı restoranlarda bu yemekler bulunduğundan } \\
\text { Lezzetli yemekler olduğundan } \\
\text { Sağlıklı yemekler olduğundan } \\
\text { Yozgat'taki önemli günlerde bu yemek ve tatlılara } \\
\text { yer verildiğinden }\end{array}$ & 5 & 20 & 17 & 68 \\
\hline
\end{tabular}

Çalışanların \%80’i Yozgat kültürünün unutulduğu görüşüne sahipken çalışmayanların ise \%68'inin tam tersi bir görüşe sahip oldukları Tablo 14'te de açık bir şekilde görülmektedir. 
5. Yozgat yöresi yemek ve tatlı kültürünün unutulmaması için yapılan önerilere ilişkin bulgular

Katılımcılardan Yozgat yemek ve tatlı kültürünün unutulmaması için önerilerde bulunmaları istenmiş ve katılımcıların verdikleri öneriler Tablo 15 'te ele alınmıştır.

\begin{tabular}{|c|c|c|c|}
\hline $\begin{array}{l}\text { Tablo } 15 . \\
\text { Katılımcıların Yozgat yeme } \\
\text { ilişkin frekans ve yüzde dağ }\end{array}$ & $\begin{array}{l}\text { ve tatlı kültürünün unutulmaması için yaptık } \\
\text { mı }\end{array}$ & & \\
\hline Kategori & Tema & $\mathbf{f}$ & $\%$ \\
\hline $\begin{array}{l}\text { Kitle iletişim araçlarından } \\
\text { faydalanılarak Yozgat yöresi } \\
\text { yemek kültürü tanıtılabilir. }\end{array}$ & $\begin{array}{l}\text { Gezelim görelim TV programlarıyla tanıtılabilir. } \\
\text { Reklamlar yapılabilir. } \\
\text { Sosyal medyada bir farkındalık oluşturulabilir. } \\
\text { Yozgat belediyesine ait site üzerinden kültürel } \\
\text { değerlere daha geniş tanıtılabilir. } \\
\text { Yozgat yöresine ait yemeklerin doğru tarifi internet } \\
\text { üzerinden yapılabilir. }\end{array}$ & 40 & 80 \\
\hline $\begin{array}{l}\text { Yeni nesle Yozgat yemek } \\
\text { ve tatlılarının yapılışı } \\
\text { öğretilebilir. }\end{array}$ & $\begin{array}{l}\text { Yemek ve tatlı kültürü nesilden nesle aktarılıp } \\
\text { öğretilebilir. } \\
\text { Üniversitelerin Aşçılık Bölümlerinde bulunan } \\
\text { öğrencilere öğretilebilir. } \\
\text { Çevremizdeki kişilere Yozgat yöresine ilişkin yemek } \\
\text { ve tatlıların tarifi verilip öğretilebilir. }\end{array}$ & 36 & 72 \\
\hline $\begin{array}{l}\text { Yozgat günleri düzenlenerek } \\
\text { bu yörenin yemek ve tatlıları } \\
\text { tanıtılabilir. }\end{array}$ & $\begin{array}{l}\text { S1k sık Yozgat günleri düzenlenebilir. } \\
\text { Farklı şehirlerde tanıtım günleri yapılabilir. } \\
\text { Fuarlarda tanıtımlar yapılabilir. } \\
\text { Yozgat'a gelen turistlere yöresel yemek ve tatlılar } \\
\text { tanıtılabilir. }\end{array}$ & 32 & 64 \\
\hline $\begin{array}{l}\text { Yozgat'la ilgili araştırmalar } \\
\text { yapılabilir. }\end{array}$ & $\begin{array}{l}\text { Yozgat yemek ve tatlı kültürünü ele alan kitaplar } \\
\text { yazılabilir. } \\
\text { Yozgat yemek ve tatlı kültürüyle ilgili elde edilen } \\
\text { bilgiler arşivlenebilir. } \\
\text { Yozgat yemek ve tatlı kültürünü iyi bilenlerin } \\
\text { videoları çekilebilir. } \\
\text { Akademisyenler Yozgat folkloruna ilişkin } \\
\text { araştırmalar yapabilir. }\end{array}$ & 25 & 50 \\
\hline $\begin{array}{l}\text { Evlerde Yozgat yemek ve } \\
\text { tatlılarına daha çok yer } \\
\text { verilebilir. }\end{array}$ & $\begin{array}{l}\text { Evlerde düzenlenen altın günü vb. günlerde bu } \\
\text { yemek ve tatlılar yapılabilir. } \\
\text { Mutfaklarda kültürel yemeklere daha çok yer } \\
\text { verilebilir. } \\
\text { Sadece annelerin yaptıkları yemekler olarak } \\
\text { görülmeyip gençler tarafından da evlerde yapılabilir. }\end{array}$ & 14 & 28 \\
\hline $\begin{array}{l}\text { Yozgat yöresine ait yemek ve } \\
\text { tatlılar satılabilir. }\end{array}$ & $\begin{array}{l}\text { Restoranlarda Yozgat yöresine ait yemeklere yer } \\
\text { verilip satılabilir. } \\
\text { Pazarlarda bu yemek ve tatlılar satılabilir. } \\
\text { Kermeslerde bu yemek ve tatlılar yap1lıp sat1labilir. }\end{array}$ & 12 & 24 \\
\hline $\begin{array}{l}\text { Yozgat yemek ve tat1ı } \\
\text { kültürüyle ilgili yarışmalar } \\
\text { düzenlenebilir. }\end{array}$ & $\begin{array}{l}\text { Yozgat Belediyesi en güzel Yozgat yemeği ve tatlısını } \\
\text { yapanlar arasında yarışma yapabilir. } \\
\text { Yozgat'ta bulunan okullarda bu yöreye ait yemek ve } \\
\text { tatlılarla ilgili bilgi yarışması yapılabilir. }\end{array}$ & 8 & 16 \\
\hline
\end{tabular}


Tablo 15 incelendiği zaman, katılımcıların bu yöreye has yemek ve tatlı kültürünün unutulmaması için çeşitli önerilerde bulundukları görülmektedir. Buna göre \%80’i kitle iletişim araçlarından faydalanılarak Yozgat yöresi yemek kültürünün tanıtılabileceğini, \%72'si yeni nesle Yozgat yemek ve tatlılarının yapılışının öğretilebileceğini, \%64'ü Yozgat günleri düzenlenerek bu yörenin yemek ve tatlılarının tanıtılabileceğini, \%50'si Yozgat'la ilgili araştırmalar yapılabileceğini, \%28'i evlerde Yozgat yemek ve tatlılarına daha çok yer verilebileceğini, \%24'ü Yozgat yöresine ait yemek ve tatlıların satılabileceğini, \%16'sı da Yozgat yemek ve tatlı kültürüyle ilgili yarışmaların düzenlenebileceğini belirtmişlerdir.

\section{Tartışma, sonuç ve öneriler}

Toplumlar kendi kültürlerini yeni nesle aktararak yaşatmaya devam ederler. Kuşkusuz ki, yöresel yemekler, kültürel mirasın bir parçasıdır ve yeni nesle aktarılması gereken en önemli kültürlerden birisidir.Araştırma kapsamında aslen Yozgatlı olan kadınların Yozgat yemek ve tatlı kültürünü ne kadar bildikleri ve bu kültürü yaşatmaya devam edip etmedikleri tespit edilmiştir.

Araştırmada yaşları 46-70 arasındaki kadınların 20-45 yaş aralığındaki kadınlara göre Yozgat yöresindeki yemek ve tatlıların neler olduğunu daha iyi bildikleri ortaya çıkmıştır. Bunun yanında çalışmayan kadınların çalışan kadınlara nazaran bu yemek ve tatlılara ilişkin bilgilerinin de daha fazla olduğu görülmüştür. Ancak Yozgat'a, Kars ve Erzurum halkının göç etmesi ve orada kendi kültürel yemeklerine yer vermeleri sebebiyle bir etkileşimin meydana geldiğini; Yozgat kadınlarının da bu etkileşimden ötürü Kars'a ait olan kesme aşı, boz aşı çorbası, haşıl ve kete; Erzurum'a has olan hasıta ve keteyi kendilerine mal ettikleri görülmüştür. Aynı zamanda Yozgat'a komşu olan illerin kültüründen de etkilenen Yozgatlı kadınların Amasya'daki dügürcük çorbası, Çorum'daki sündürme yemeği, Tokat'taki bat yemeği ile Sivas ve Tokat'taki ekmek aşı çorbasını da kendi yemek kültürüne dâhil ettikleri ortaya çıkmıştır.Düzgün ve Özkaya'ya (2014) göre de göçler ve yer değiştirmeler yemek kültürünün belirlenmesinde önem teşkil etmiştir.

Yozgat yöresine ait yemek ve tatlıların yapılışı ile ilgili elde edilen bulgulara bakıldığında, 46-70 yaş arasındaki ve çalışmayan kadınların büyük çoğunluğu, 20-45 yaş arasında ve çalışanların ise çok azı bu yöreye özgü yemek ve tatlıların yapılışlarını bildiklerini dile getirdikleri görülmüştür.Kadınların vermiş oldukları bu bilginin doğruluğunu kanıtlamak amacıyla da onlardan yemek tarifleri istenmiş ve 46-70 yaş arasındaki kadınların büyük çoğunluğunun birçok yemek tarifini doğru verdiklerine ancak 20-45 yaş arasındakilerin ise çok azının birkaç yemek tarifini doğru verdiklerine rastlanmıştır. Aynı zamanda çalışmayan kadınların çoğunluğunun, çalışanların ise çok azının bu yemek tariflerini doğru verdikleri tespit edilmiştir.Yöresel Yozgat yemekleriyle tatlılarının yapılışını bilmeyenlerden bu yemek ve tatlılarda kullanılan malzemeleri yazmaları istenmiş;20-45 yaş aralığındaki birçok kadın, 46-70 yaş aralığındaki birkaç kadın bu soruya yanıt vermiştir. 46-70 yaş aralığındaki kadınların büyük çoğunluğu bu yemeklere ilişkin tam tarif verdiklerinden 46-70 yaş aralığındaki kadınlardan çok azının bu soruya yanıt verdikleri görülmüştür. Bu sebeple 20-45 yaş aralığındaki kadınların 46-70 yaş aralığındaki kadınlara göre daha fazla bilgi verdikleri tespit edilmiştir. Çalışmayan kadınların çalışanlara göre çok az bir farkla bu yemek ve tatlılarda kullanılan malzemeleri daha iyi bildiklerine de rastla- 
nılmıştır. 20-45 yaş aralığındaki ve çalışan kadınların neredeyse yarısı bu yemekleri oldukça zahmetli buldukları için yapamadıklarını aktarmışlardır.

46-70 yaş aralığındaki kadınların 20-45 yaş aralığındakilere nazaran evlerinde Yozgat yöresine ait yemeklerle tatlılara daha çok yer verdikleri tespit edilmiştir. 46-70 yaş aralığındaki kadınların evlerinde yöresel yemeklere çok fazla yer vermelerinin sebepleri ise şunlardır: Lezzetli bulmaları, sağlıklı yemekler olması, ailedeki kişilerin bu yemekleri sevmesi, damak tatlarına uygun olması, kültürlerini yansıtması, kültürel yemekleri benimsemeleri.Ayrıca çalışmayan kadınların büyük çoğunluğunun, çalışan kadınların ise çok azının evlerinde Yozgat yöresine ait yemeklerle tatlılara yer verdikleri sonucu da elde edilmiştir. Bu bulguyla örtüşen Akkuş’un (2019) çalışmasında, evde geçirilen sürenin artışına bağlı olarak söz konusu yemeklere de ayrılan sürenin arttığı ve çeşitliliğin korunduğu belirtilmiştir. Yine Akkuş, orta yaş üstü kadınların önemli bir kısmının herhangi bir işte çalışmadığı için yemeklere daha fazla süre ayırdıklarını da ortaya koymuştur. Sered (1988) de, yaşı kadınların yemek konusunda gösterdikleri hassasiyetin nesiller arasındaki ilişkiler ağının da bir destekleyicisi olduğunu aktarmıştır.

20-45 yaş aralığındaki kadınların birçoğu Yozgat yöresi yemek ve tatlılarının unutulduğunu söylerken 46-70 yaş aralığındakilerin birçoğu da bu yöreye ait yemek ve tatlıların unutulmadığını dile getirmişlerdir. Çalışanların çoğunluğu Yozgat kültürünün unutulduğu görüşüne sahipken çalışmayanların birçoğunun ise tam tersi bir görüşe sahip oldukları görülmüştür.46-70 yaş aralığında ve çalışmayan kadınlar, Yozgat yöresi yemek ve tatlılarının hem yapılışını çok iyi bildiklerinden hem de Yozgat'a ait yemek ve tatlı kültürünü yaşattıklarından bu kültürün unutulmadığını düşünmektedirler. 20-45 yaş aralığında ve çalışan kadınlar ise, gerek Yozgat yöresi yemek ve tatlılarının yapılışını çok iyi bilmemelerinden gerekse Yozgat'a ait yemek ve tatlı kültürünü yaşatamamalarından bu kültürün unutulduğu kanısındadırlar.

Araştırmada Yozgat yöresi yemek ve tatlı kültürünün unutulmaması için katılımcılardan çeşitli öneriler de istenmiştir. Böylece katılımcılar, kitle iletişim araçlarından faydalanılarak Yozgat yöresi yemek kültürünün tanıtılabileceğini, yeni nesle Yozgat yemek ve tatlılarının yapılışının öğretilebileceğini, Yozgat günleri düzenlenerek bu yörenin yemek ve tatlılarının tanıtılabileceğini, Yozgat'la ilgili araştırmalar yapılabileceğini, evlerde Yozgat yemek ve tatlılarına daha çok yer verilebileceğini, Yozgat yöresine ait yemek ve tatlıların satılabileceğini, Yozgat yemek ve tatlı kültürüyle ilgili yarışmaların düzenlenebileceğini aktarmışlardır.Erdem, Mızrak ve Kemer'in (2018) araştırmasında, ulusal ve uluslararası anlamda yöresel yemeklerin tanıtımlarının sağlanması gerektiği ve yapılan tanıtımların yetersiz olduğu belirterek yöresel yemeklerin tanıtımını sağlamak amacıyla fuar ve yarışmalarda tanıtımların yapılması, okullarda yöresel yemeklere yönelik eğitimler verilmesi, TV programları ve sosyal medyanın tanıtım aracı olarak kullanılması gerektiği, derneklerin, belediyelerin de bu tanıtımda destek vermesinin oldukça önemli olduğundan bahsetmiş ve bu araştırmanın bulgularıyla örtüşen bazı sonuçlara ulaşılmıştır.

$\mathrm{Bu}$ çalışmada bulgular genel olarak değerlendirilip özetlendiğinde, iki önemli sonucun öne çıtı̆̆g görülmektedir. Bunlardan birincisi, eski neslin (46-70 yaş) yeni nesle (20-45 yaş) nazaran kültürel değerlerine daha çok bağlı oldukları ve yemeklerle tatlı kültürünü yaşattıklarıdır. Aynı zamanda eski neslin yemek ve tatlı kültürü konusunda daha geniş bilgi birikimine sahip olduklarıdır. Ancak buna rağmen Yozgat yöresindeki birçok yemek ve tatlıdan da hiç söz edilmediği dikkat çekmektedir. Bunlar arasında çiğdem pilavı, yarma aşı, yumurta tatlısı, mısır tatlısı, ekşili 
kabak, gınnıç, tene pilav vs. sayılabilir. Bundan ötürü Yozgat'a ait bazı yemek ve tatlıların yavaş yavaş unutulmaya yüz tuttuğu söylenebilir. İkincisi ise, çalışmayan kadınların çalışan kadınlara göre yemek ve tatlı kültürü konusunda daha geniş bilgi birikimine sahip oldukları ve bu kültürü yaşatmaya çalıştıklarıdır. Araştırma sonuçlarından hareketle Yozgat yemek ve tatlı kültürünün sürdürülebilmesi için aşağıdaki önerilerin yerine getirilmesinde fayda olduğu düşünülmektedir:

- Yozgat yöresindeki okullarda bu yöreye has yemek ve tatlılar hakkında geniş bilgi verilebilir; panel, konferans vs. yapılabilir.

- Yozgat yöresindeki okullarda seçmeli dersler aracılığıyla Yozgat yemek ve tatlıları öğretilebilir.

- Türkiye'nin çeşitli illerinde Yozgat günleri yapılarak bu yemek ve tatlılar tanıtılabilir.

- Unutulmaya yüz tutmuş yöresel yemek ve tatlıların yaygınlaştırılması konusunda Yozgat halkı bilinçlendirilebilir.

- Araştırmacılar tarafından Yozgat kültürüne ilişkin henüz gün yüzüne çıkmamış yeni bilgiler derlenebilir.

- Pazar ve panayır gibi yerlerde Yozgat yemek ve tatlıları satılabilir.

\section{Kaynaklar}

Akkuş, Ç. (2019). Yemek kültürünün sürdürülebilirliğini kadınların demografik özellikleri etkiliyor mu? Journal of Tourism and Gastronomy Studies, 7(2), 731-750.

Büyükşalvarc1, A., Şapcılar, M. C. ve Yılmaz, G. (2016). Yöresel yemeklerin turizm işletmelerinde kullanılma durumu: Konya örneği. Journal of Tourism and Gastronomy Studies, 4(4), 165-181.

Çağlayan, S. (2011). Göç kuramları, göç ve göçmen ilişkisi. Sosyal ve Beşeri Bilimler Araştırmaları Dergisi, 17, 67-91.

Çelik, M., Aksoy, M. ve Özkaya, F.(2017). Bozok Üniversitesi öğrencilerinin Yozgat yemeklerini tanıma düzeyi. II. Uluslararası Bozok Sempozyumu bildiriler kitabı içinde (s.56-69). Yozgat: Bozok Üniversitesi.

Düzgün, E. ve Durlu Özkaya, F. (2015). Mezopotamya'dan günümüze mutfak kültürü. Journal of Tourism and Gastronomy Studies, 3(1), 41-47.

Erdem, Ö., Mızrak, M. ve Kemer, A. K. (2018). Yöresel yemeklerin bölge restoranlarında kullanılma durumu: Mengen örneği. Uluslararası Türk Dünyası Turizm Araştırmaları Dergisi, 3(1), 44-61.

Serçeoğlu, N. (2014). Yöre halkının mutfak kültürünü tanıma durumunun tespit edilmesi: Erzurum ili. Journal of Tourism and Gastronomy Studies, 2(4), 36-46.

Sered, S. S. (1988). Food and holiness: Cooking as a sacred act among middle-eastern jewish women. Anthropological Quarterly, 61(3), 129-139.

T.C. Yozgat Valiliği (1991). Yozgat 1991 il yıllı̆̆g. Ankara: Yozgat Valiliği.

Yurt, R. (2016). Nüfus yaş ve cinsiyet gruplarının göçe etkisi (Yozgat örneği). I. Uluslararası Bozok Sempozyumu bildiriler kitabı içinde (s. 467-484). Yozgat: Bozok Üniversitesi.

\section{Elektronik kaynaklar}

T.C. Yozgat Valiliği İl Kültür ve Turizm Müdürlüğü. Yozgat mutfağı ve yöresel yemekleri. https:// yozgat.ktb.gov.tr/Eklenti/52544,yozgat-mutfagi-ve--yoresel-yemekleripdf.pdf?0 adresinden edinilmiştir. 


\section{ETIK KURUL BILDİRIMI}

Bu makaleye ilişkin olarak;

Yakın Doğu Üniversitesi

Bilimsel Araştırmalar Etik Kurulu'nun 24.11.2020 tarihli ve Kurul Başkanı Prof. Dr. Rüştü Onur imzasıyla dergimize iletilmiş olan belgeyle etik açıdan oybirliğiyle olumlu görüş bildirilmiştir.

Söz konusu belge dergi yönetimince arşivlenmiştir.

\section{folklor/edebiyat dergisi}

